\title{
Article
}

\section{Urban Architecture as Connective-Collective Intelligence. Which Spaces of Interaction?}

\author{
Andreina Maahsen-Milan ${ }^{1, *}$, Margot Pellegrino ${ }^{2, \dagger}$, Luigi Oliva ${ }^{3, \dagger}$ and Marco Simonetti $^{4, \dagger}$ \\ 1 Department of Architecture, University of Bologna, Via Risorgimento 5, Bologna 40126, Italy \\ 2 Centre de Recherche sur l'Habitat (CRH), UMR-CNRS, 7218-Lavue, France; \\ E-Mail: margot.pellegrino@paris-valdeseine.archi.fr \\ 3 Department of Architecture, Design, Urban Planning, University of Sassari, Palazzo Pou Salit, \\ Piazza Duomo 6, Alghero (SS) 07041, Italy; E-Mail: luigi.oliva@uniss.it \\ 4 Energy Department, Polytechnic of Turin, C.so Duca degli Abruzzi 24, Torino 10129, Italy; \\ E-Mail: marco.simonetti@polito.it
}

$\dagger$ These authors contributed equally to this work.

* Author to whom correspondence should be addressed; E-Mail: andreina.milan@unibo.it; Tel.: +39-544-936-511; Fax: +39-544-936-503.

Received: 22 April 2013; in revised form: 24 June 2013 / Accepted: 26 June 2013 /

Published: 4 July 2013

\begin{abstract}
During the twentieth century, with the advent of industrial society and globalization, the language of planning changed according to the shifts in construction and use of physical space. By borrowing terms and spatial forms from biology and cybernetics, industrial society and globalization increased the original semantic connotations. Moving from cognitive sciences, this paper outlines the definition of architecture as connective-collective intelligence and presents its implication in urban design. Spontaneous and commercial initiatives are redefining the communication form of urban life, affecting the procedures of the transmission of traditional knowledge. This approach to building environment is moving towards a complex multichannel interaction, involving both the individual and the collective experiences of space and technology. In describing some signs of that process, the authors outline new features that are changing the concept of sustainability in urban design.
\end{abstract}

Keywords: urban architecture; sustainable developments; city as a "complex adaptive system"; thinkering; uncertain models; collective mind 


\section{Introduction}

During the twentieth century, with the advent of industrial society and globalization, the language of planning changed according to the shifts in perception and the use of physical space. By borrowing terms and spatial forms [1] from biology and cybernetics, their original semantic connotations increased. The paper's subject is the perceptive mutation of the idea of city in a perspective of complex systems. Its aim is to verify through examples and applications how disciplinary crossbreeding, the holistic approach and the establishment of connective networks (the so-called cognitive-connective intelligence) can prompt transformations in the use of openly-built public and private spaces that offer an innovative physical layout and aggregative modalities that overcome the traditional urban governance and space design practice.

A short excursus into the evolution of language, the interdisciplinary conception of the architecture of the contemporary city and its subjective/objective crossbreeding can account for possible paths in new urban contexts in order to sketch present and future feasible solutions.

Issues, such as participation, design education and innovation are discussed throughout the chapters. These issues are presented not to summarize a conclusive projection of the city's future, but rather to open up a discussion. Questions about living in a technologically-driven society, issues of education through exhibitions and the creation of collaborative structures are addressed. This paper is a general overview of how not just architects, but citizens, in general, think about their man-made environment [2]. It has been structured in a fragmented logical form that tries to reflect the complex interaction of the described trends. Through European case studies, this paper aims to investigate how such crossbreeding has permanently conditioned the perception and use of space. Space is seen as a "form of extension of the intelligence and private memory made collective". This means that implementing a change in decisional rules and governance can occur by establishing a closer relationship with citizens or stakeholders.

\section{Methodological Crossbreeding: Architecture as Connective Intelligence}

Architectural design, including the one that refers to Cyber culture, has been criticized as being too self-referential, because it shows disturbing analogies to politics, which are incapable of representing the reality and collective requests and values. The controversy has found several and reasonable opportunities for manifestation, especially with regards to the scenographic, often inconsistent research for formal novelties, proposed by "archistars", whose media impact on print and digital magazines has contributed to proliferation across the country [3].

There is no doubt whatsoever that in the past two decades and in the current situation of the crisis of economic development models, and of any other models, the debates over sustainability and de-growth confront each other. The holistic approach in the research of urban sustainable solutions moved from technological problem solving [4] - by proposing adaptive and self-sufficient dynamic buildings - to the vision of the city as a "complex adaptive". To manage this complex system, which consists of applicative potentialities, it is necessary to introduce "open systems" and the collective-connective intelligence in the field of architectonic urban design processes. 
The multidisciplinary integration with the social sciences, therefore, appears very appropriate and necessary to unblock the cultural impasse of metropolis and human community development models. Today, the future of the city is not evaluated with axiomatic conceptions or economic algorithms; on the contrary, it is based on common practices of "thinkering" [5]: operative evaluations projected on "uncertain models" [6] or "resilient" [7] ones in a global system prone to skepticism [8].

It is this point of view that refers to the theory of complex systems. It is still premature to evaluate the effects and relapses of this methodology on urban design, but it certainly has generated an uncommon awareness, at a global level, of problems and their interdependency in human history. The rapid diffusion across the West of social networks promoted the connection between very far realities, subject to similarities and oppositions that are created when searching for cultural reading levels that highlight salient points, encouraging a field observation, rather than virtual ones.

\section{Tesserae for the History of Crossbreeding Experiences}

This part of the paper introduces a series of tesserae, i.e., elements and considerations about the interconnections between art, architecture, urban planning and technology. This part tracks some of the most significant and fecund steps of cultural crossbreeding between art, space and science. Technologue hegemonies, which sometimes reduce the scope of the action of users and consumers, can also act as a means for enhancing their opportunities. The concept of collective-connective intelligence arises from those considerations and points at identifying a logic of positive interaction.

\subsection{Art, Space and Science}

Pierre Lévy's statement "[...] we are building a humanity which seems closer to itself" pointed out how the burst of cybernetics into everyday life glorified collective and biological-cognitive functions by accompanying and crossbreeding them, not by replacing them with the laws of physics, optics and mechanics. This dynamic was the result of a shift in a long ontological and technological process that had been investigating the relationship between reality and subjective observation, between "sensible" worlds, immaterial and separated "kingdoms" - as the thread of continuity of current events shows, which started in mainland Europe and America during the second half of the twentieth century.

At the beginning of the twentieth century, Ernst Haeckel (1834-1919) was investigating biological marine forms to propose — on the basis of an excellent graphic system [9] — considerations and stimuli on "alien" forms of life that are still present in the sensible universe (see Figure 1a). The fortune and circulation of his work among scientists and educated people allowed "spurious" artists with a solid theoretical basis, such as Hermann Obrist (1862-1927), to tap into the inexhaustible formal, structural and semantic repertoire of organically shaped forms [10].

The novelty inherent to Art Déco and Jugendstil was not about invention, but the fact that it faithfully reproduced, described and observed the objective physical reality, though in a different scale and integrally decontextualized. Thanks to innovative photographic technologies and Röntgen X-rays, the scientist-artists of the early 1900s investigated the matter and revolutionized the representation processes starting from objective-subjective vision, utilizing modalities that were later known as "Pop Art".

Photographer-sculptor, Karl Blossfeldt (1865-1932), spokesperson of the so-called Poetic Darwinism, opened up the crossbreed between art and science. He launched networks and logical-formal 
connections between daily routine and "Urformen" (the primitive structures of organic matter) with the intent of investigating and reproducing its complexity and harmony (see Figure 1b) [11].

Man Ray (1890-1976) started with the same premises, but imposed that skeptical side that belongs to "Dada". He experimented with the effects of casually matching objects and situations in a voluntary process of randomization that created completely unexpected idiomatic expressions (see Figure 1c).

To a certain extent, this attitude is similar to Frederick John Kiesler's theoretical and artistic work (1890-1965), who was the spokesperson of dynamic-spatial architecture (see Figure 1d) [12]. Kiesler stated: "We want abodes where elasticity is like vital functions. [...] Let's give people social security; let's give builders the freedom to create; let's give the industry scientific directives. Then, a popular architecture will gradually and naturally develop. Since, its nature is made up of the willingness to adapt to life's circumstances, to the laws of society, in order to create and transform, for which it takes its own part of responsibility" (excerpt from: “Manifeste du Corréalisme”, 1949) [13].

\subsection{Architecture, Space and Science}

Kiesler's biographical-cultural parable shows curious analogies with Carlo Mollino [14] regarding the role that his teachings played in the architectonic thought of the second half of the twentieth century. His didactics and interconnected forms, languages, abstract concepts and experimentations were presented in a consistent crossbreeding and storytelling process, which continuously hovered between nature and artifice [15].

Almost a century later, theorists, like Australian, Ross Rudesh Harley, and Colombian, Maria Fernanda Cardoso, are following with the intent of starting up the cultural, artistic mix (see Figure 1.e). These theorists are experimenters of the cyberculture, where "the bounds of media art practice, cinema, music, design, and architecture" meet. Marcos Novak (born 1957) is also a crossbreeding theorist, initiator and major exponent of "Liquid Architecture" and "Transarchitecture" trends. He "utilizes mathematical algorithms to build hybrid and intelligent spaces to create new architecture [...] capable of merging the two worlds, real and virtual, generating a third one" [16]. Novak states that "[...] ideas are the invisible scaffolds upon which the real is constructed". The history of architecture is a history of the increasing elaboration of invisible scaffolds. There are literal scaffolds and there are information scaffolds that connect human interests and activities across the vastness of distance and knowledge" [17]. Again, it was Novak (2000) who tried "to demolish the traditional monolithicity of design disciplines to assimilate them to artificial sciences" [18], so that "they are face-to-face with an unprecedented perspective: to extend design to all levels" in an architecture that accepts and owns the post-Euclidean dimension.

\subsection{Web Space and Open Systems: New Accounts between Time and Space}

For some decades, the themes of continuity and space-time dimension have polarized the interest of visual artists and mass-media communication. The steady success of the cultural time capsule theme proves it in its move from cognitive sciences to cinema, literature and television. The TV series, Lost, is an extraordinary example; filmed using flashback, flash-forward and flash-sideways techniques, it proposes a non-linear reading of space-time, which is a parallel experimentation; according to 
Edward De Bono's definition (born 1933), lateral means structured as a hypertext that eventually merges in a unique narrative solution [19].

Figure 1. (a) E. Haeckel, from "Art Forms from the Ocean", 1904; (b) K. Blossfeldt, Haarfarn from "Urformen der Kunst", 1929; (c) Man Ray, "Clock Wheels", 1925; (d) F. J. Kiesler, "Endless House and its Psychological Lighting", 1959; (e) (CWikimedia Commons); M. F. Cardoso, "Woven Water: Submarine Landscape”, 2003 (C M.F. Cardoso).
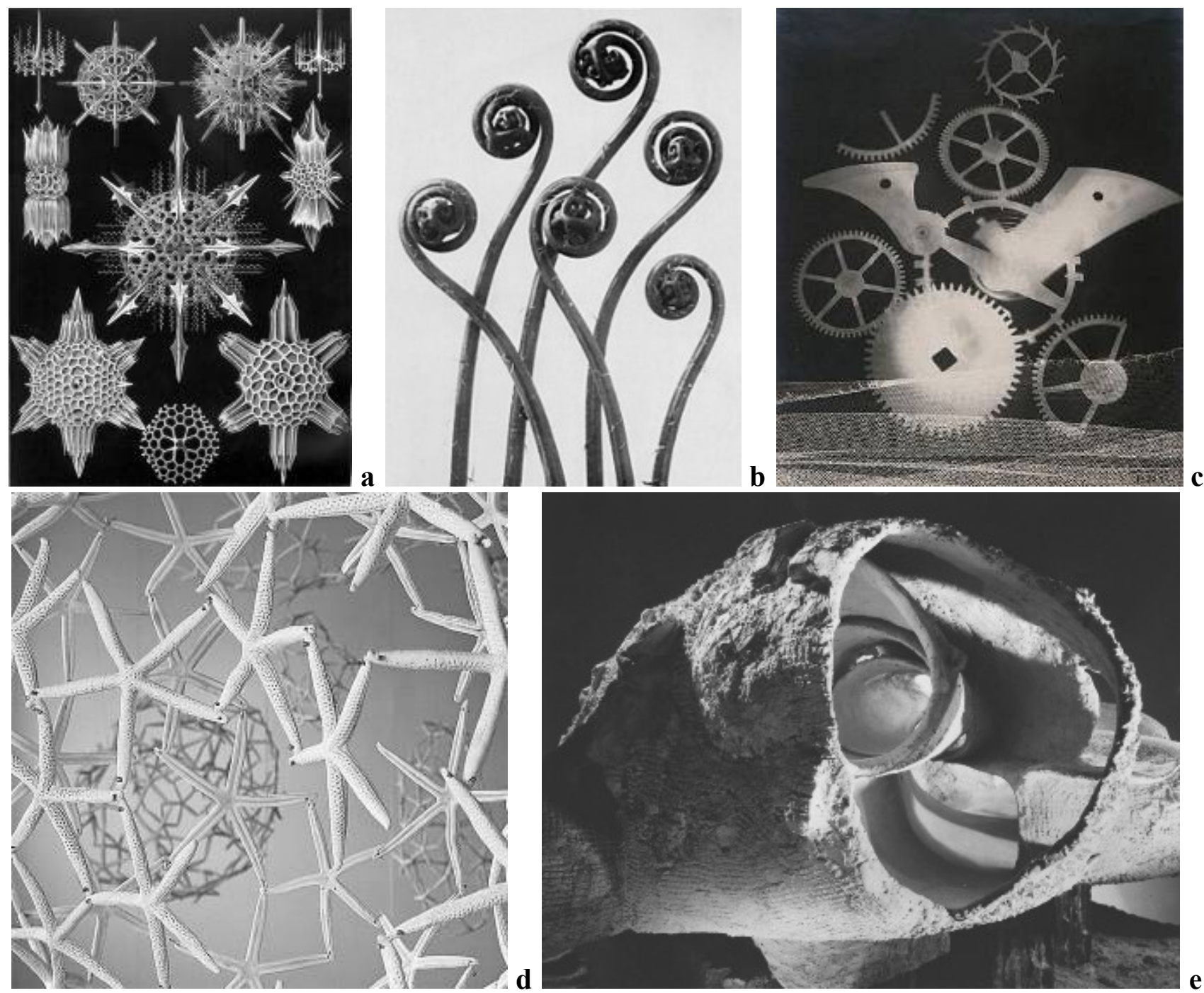

Regarding matters linked to cognitive science studies, such as the problem solving capability, sociologists, philosophers and psychologists have been utilized in the field of artificial intelligence and mass-media communication. In the early 1990s, the theory of connective-collective intelligence was developed, thanks to the conversations that took place in Amsterdam between two collaborators and pupils of Marshall McLuhan, Pierre Lévy and Derrick De Kerckhove.

Yet, it is the latter that resumed and elaborated the concept of collective intelligence (Levy) as a product of the memory and collective imaginary, which becomes a project when the instruments that allow or encourage the interaction between individuals are made available. Its extension to the web suggests the development of the "connective intelligence theory", where nodes are what matters. 
The connective intelligence is an incremental factor, a multiplier of intelligences, made possible by their connection rather than their sum. It is no accident that the theories of connective intelligence by De Kerckhove stemmed from Harley's ideas.

According to whom, the idea of collective intelligence (closed container) must be overcome because it is the "web space" that builds an "open system", to establish connections "from person to person" inside a very specific network. The specificity of which is not represented by the collective container of knowledge. A valid example is the "p2p" (peer-to-peer) exchange system.

\section{Experimental Section}

The tesserae introduced in previous paragraphs aim to provide food for thought about some innovative topical nodes: the methodological and trial crossbreeding that exists between art and technology, especially in communication technologies; the progressive shift towards closer and closer interactions between the object and user; and above all, the simultaneous participation of networks and different systems to build artistic, architectonic and urban events.

In this section, we propose case studies that intend to illustrate a part or a series of a set of different parts previously introduced. It is a collection, apparently not organic, of projects and events that have been carried out recently in Europe, mainly in Italy. This collection is organized around a common core, represented by the high level of interaction between "object" and "individual", which takes on different shapes.

The first case study is about an "interactive museum", for which the idea of "connection" develops from different communication plans. This first occurs from the relationship that the visitor establishes with the exhibition space and, finally, broadens to a wider network developed in an institutional, didactic and scientific context. In the second and third case studies, we analyze the concept of active and creative participation applied to different types of events. In the fourth case study, we read a technological system from an engineering point of view, in light of possible interactions with the user and the urban network, from a viewpoint of multi-scale interconnection. Beyond the communal approach, each contribution identifies innovative aspects related to its own project through brief illustrations.

\subsection{An Interactive Museum on the Net ["A come Ambiente" ("E for Environment") Turin, Italy]}

The museum "MA-A come Ambiente" opened in Turin in 2004, thanks to the renovation and redesign plan of new spaces inside a big abandoned industrial estate. This is the first museum in Europe thoroughly dedicated to environmental themes, such as energy, ecology, consumerism, transport and food. The ideation, construction and exhibition set-up and fruition stages are innovative and interesting, especially from the point of view of complexity, flexibility and multimedia management (both in the architectonic shape and in the possible use of spaces).

The article outlines the following construction phases of the museum: the structure, the spatial organization, the fruition modalities and the internal management system. The foundation process of this structure was inspired by the convergence of different actors, who had a lengthy experience in the event and exhibition management. The ability to pool and value existing practices was made possible thanks to the creation of a network of diversified subjects. A big experimentation and organization 
package merged into a uniquely designed project. The outcome was the museum, which represents the climax of a journey divided into many stages. MA started from the development, evolution, remake and innovation of the interactive and multimedia museum.

Permanent and interactive multimedia exhibitions, like "W for... how to know and play with Waste" ("R come... conoscere e giocare con i Rifiuti") "H2O, know and play with Water", and Bio.net, know and play with genome", achieved resounding success in the past years. MA is rooted in the popular didactic culture, which developed and became very popular in Turin, from "art lab" to "experimental", to popular science evenings, "Science Thursdays" and "Next", and the exhibitions in preparation of a future project of the "science center". The space organization and the fruition modalities represent an example of how flexibility can become a valuable paradigm of a cognitive and experiential process (see Figure 2). The keyword is "adaptability".

Figure 2. (a-c) "A come Ambiente" Museum, Turin. Exhibition halls-interior. [photos@Margot Pellegrino].
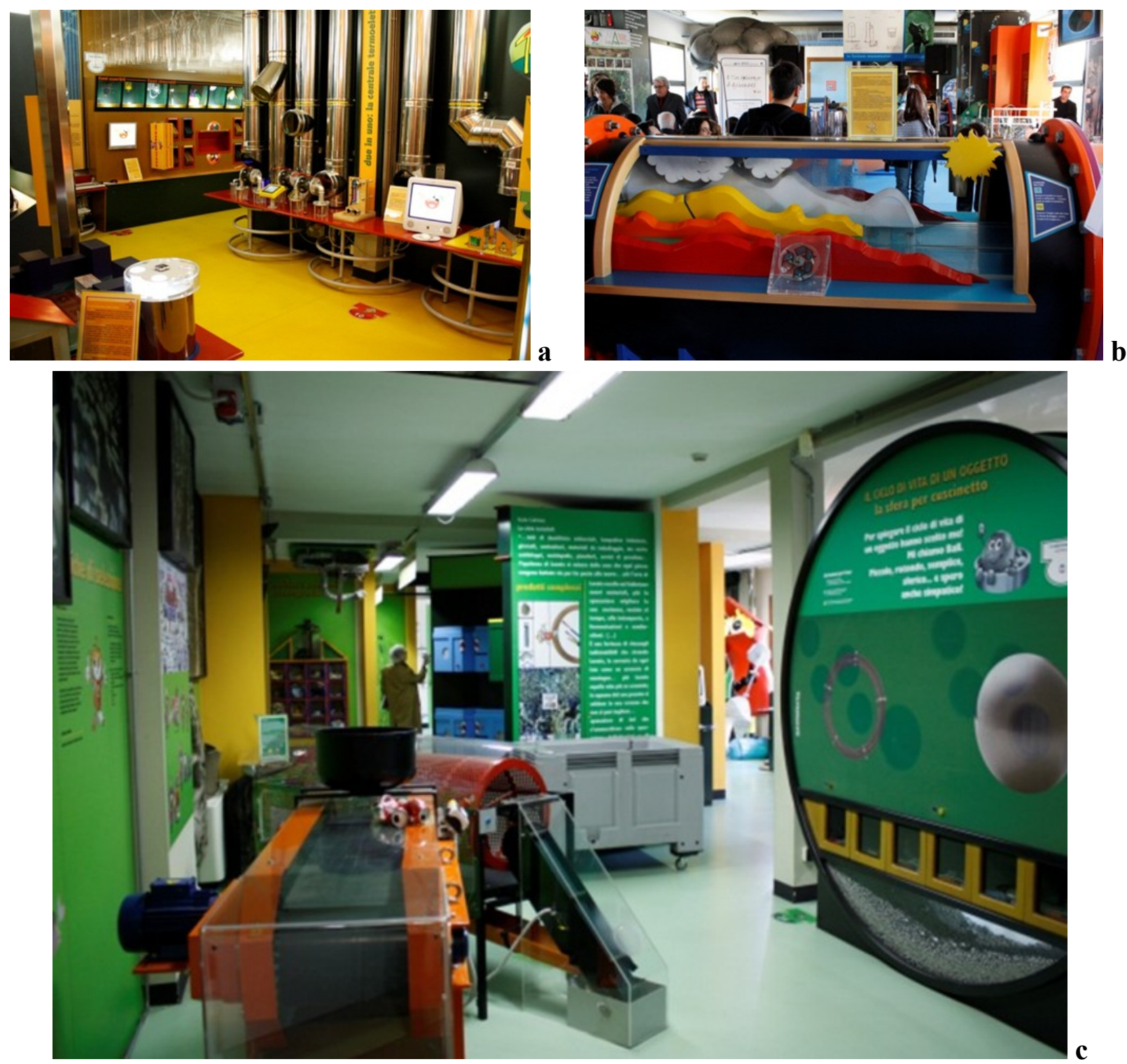
The structure of the building is conceived to allow varied installations and a continuous transformation of spaces: set-ups can be modified, as well as itineraries. The interaction between the building/set-up/user is at the center of the museum concept, elaborated by the designer, Prof. Arch. Agostino Magnaghi, and by the museum director, Dr. Carlo De Giacomi. The role of the visitor is not passive; one can intervene, touch, experiment and use the installed mechanical and multimedia devices, based on the idea of "learning through play". Depending on the degrees of difficulty, time and interest, the itinerary adapts to a differentiated audience (from children to adults) and to different themes (visible in their globality inside an ongoing itinerary). It is a knowledge that can focus on the detail, on a specific theme and compare itself in a multiscalar vision, such as the heating system of a building to the more general theme of air pollution.

The internal management system at MA is equally interesting, as the building is not only an interactive, multimedia museum, but is an experiment and a crossbreeding. MA organizes events and exhibitions about current affairs by offering a critical point of view about the examined themes. It is connected with education institutions, companies, agencies, associations and others interested in the environment. MA is also a workshop and a place of simultaneous production of knowledge and materials. The interactive and multimedia set-ups were conceived, designed and made ad hoc by an internal team (called the "Creative Workshop"), which is composed of employees, collaborators and consultants.

\subsection{The Role of the Net: Active Citizenship and Urban Governance [the "Biennial of Public} Space"-Rome, Italy].

The "Biennial of Public Space" was born in the last months of 2010, and the project was carried out by the historic and prestigious INU (National Institute of Urbanistics) to achieve a common table of discussion about the meaning, construction and management of collective spaces. Its open, creative and interactive character represented a turning point in the elitist and traditionally closed management of Italian urbanistics. The hybrid and participative character of the events developed over a few months and almost exclusively through the Internet and social networks, exceeding the most optimistic forecasts of organizers with regards to the volume of proposals. The three-day celebration in Rome, from May 12 to 14, 2011, occurred in a pioneering and playful way inside the construction site of the University of "Roma Tre". The event consisted of round tables, workshops, design exhibitions and videos performed during the renovation of the ex-slaughterhouse in the old and very popular area of Testaccio. The second edition of the Biennial, from May 17 to 19, 2013, characterized itself for the presence on the Internet with mixed modalities, properly, associative-analogical, where the role of the associative-digital groups is rapidly growing, thanks to social networks.

There are self-convoked groups of the so-called "active citizenships" that are building social lobbies, according to a new associative phenomenon [20] focused on "city making", on a participative basis. The transformation is consolidating with the choice of opening the debate to unconventional "actors", such as groups of "guerrilla gardeners", sociologists and artists, who debate over and compare their ideas and experiences, from performance to flash mob, with traditional technical figures, such as public administrations and private entrepreneurs. 
As a matter of fact, this ability to team up coincides with the experimentation of team telework located in different areas of the country or in a transnational dimension. The crucial transition is kept on the efficacy of the medium and, above all, on the ability to overcome the communicational linguistic barrier. The construction of current "test cities" was born in the creation of "conventional" languages, such as shared elements in keywords with a global and glocal value.

\subsection{Action, Denial, Reaction: New Boundaries of Creative Participation [Taranto, Italy]}

The consideration of bottom-up processes in the sphere of research on new forms of interpretation and development of the urban space concerns a vision of the city in which, through the multidisciplinary development of enquiry, economics and human sciences, are levelled to technical disciplines. The approach that derives from it is experimental and open, characterized by methodological, instrumental and systemic aspects, rather than obsolete axiomatic models with disaggregating effects on conditioned planning [21]. In particular, new interpretative horizons come from the acknowledgement of the "economic value" of the informal (in the global macroeconomics scale and in the local scale of the perception of urban spaces, with particular attention to the empty and marginal) [22]. The disciplines of sociolinguistics, with an enquiry about expressive manifestations, the linguistic symptomatology of the conception of space and the relationship of community-city [23] are disciplinary fields of great interest.

Throughout the history of participative experiences, a huge bibliography has been created, which offers information on collective actions, artistic and/or social devices and spontaneous and adaptive manifestations. Among them, the work of Riccardo Dalisi catalyzed childish creative disorder, elevating it to a social game for the production of the Architecture of the Unpredictability, in the highly deprived Traiano neighborhood in Naples [24].

Those experiences, compared to a general context, refer to a "lateral" approach freed by the will of the control of processes. This approach promotes the free exercise of creativity, and its aim is to recover more intense and efficient practices of interaction with urban space. The scenario is more similar to the spontaneous city, which is generating new urban models in South American suburbs [25].

The methodology is "collective-connective", oriented to co-action among peers, typical of web platforms that are conscious of the balance of forces internal to individuals and social and community fabrics. The creative process could be defined "postdesign", intended as a product rich in suggestions and emotional power, able to involve participants and observers, cancelling the distance between the manufactured product and the artistic dimension of design.

The debate over urban performative creativity made a comeback at the end of the twentieth century, with the crisis of the consumerist-capitalistic model and the research for new sustainability policies. In the social sphere, the value of place identity asserted itself, also in a promotional key, as a substructure of self-identity, characterized by cognition, memories and affection clusters concerning tried out places. It is conceived like active personal constructions, stemming from the direct experience of the physical environment and endowed with "structural properties that dynamically vary in relation to the social identity and to the lifestyle of individuals" [26-28].

Those assumptions paved the way for the 1991 "Charter of Educating Cities" in Barcelona [29], but they found no proper declination in urban planning, where informal actions rarely drifted away from the paltry role of ephemeral expressions, like street art and graffiti. Indeed, the traditional urban design 
perspective is geared to the control of processes, rather than to co-action within cultural scenery, where the crossbreeding device proceeds from a centralistic vision.

When performed in urban areas, connective-collective participative actions proved to be able to re-establish the historic continuity in neighborhoods marked by functional decay through the capability of "mnemonic gluing" to integrate the connective, historic tissue of spaces that are no longer adjoining [30]. To reach this target, a partial handover of power is needed in order to involve the informal productive processes of architecture and design.

The European and Mediterranean city — with its complex system of relations and disarticulations, between historic-traditional values and property speculation - is the field of this new season of the experimental participative approach. Apulia is one of the Italian regions that is more active in this context, where the youth initiative for the design of confrontation places in cities has been funded for many years with experimentations of new economic and research models. A lot of these projects concern the urban space in its most disparate declinations.

A relevant case study is the city of Taranto, characterized by an exaggerated polarization of the territory, due to the presence of heavy industry and strategic military structures. The effects produced by the speculative and uncultivated declination of urban trends (renewals and gentrification of city centers, creation of satellite suburbs, development of metropolitan linear areas and fiscal zoning) have conformed a municipal territory marked by deteriorated areas surrounded by anonymous or dormitory suburbs.

In the city center, a group of designers and cultural operators started up an Urban Center, the "Maggese site" in 2006, in a neighborhood marked by abandonment and underaged illiteracy. The intent was to create a cultural exchange center, utilizing the disused public property asset. In 2008, the cinematographic medium became the opportunity to open the debate over the future vision of the neighborhood. In 2009 to 2010 , three initiatives funded by the region [31] promoted practices of material and linguistic redefinition of spaces by involving the population in the design stage and introducing sustainable construction techniques of raw soil and recyclable materials. In 2011, a project began to start up for unemployed residents to artisanal production and building sites (National Operative Plan, Safety for Development, Objective, Convergence, 2007 to 2013) [32].

All the activities were promoted, discussed and documented as a testimonial of the transformation of participative moments in actions of involvement and interpretation of the space (see Figure 3a,b). All those activities could not activate permanent processes, and the reasons can be found both in the inefficiency of the municipality and in the influence of the local oligarchy that grew rich in a territory marked by fragmentation, deprivation and a lack of public control, enhanced by the disintegration of social communities.

For a better understanding of the value of sustainability in urban practices, we can compare two current projects. The first project is called "Landscape Choreography: from Waste Lands to Shared Urban Gardens" and has been co-funded by the EU Culture Programme, 2007 to 2013 [33]. It proposes the planting of allotments in four urban realities, Taranto (Italy), Cluj-Napoca (Romania), Cottbus (Germany) and Łódź (Poland), to develop participative and artistic production processes in an urban emptiness.

The second project is an "urban center" partly funded by the Apulia Region, called "Ex-Fadda" [34], at San Vito dei Normanni (Brindisi), where groups of creatives and volunteers are transforming a 
former oenological plant, "Dentice di Frasso", into a multifunctional space conceived for the enhancement of cultural opportunities in the surrounding area. In the first project, from the European scale to the local one, the municipality is running the risk of losing the action, because of bureaucratic and economic difficulties. In the second case, from the local scale to the transnational one, the acquired awareness of the economic-social value by the network of districts and local governments is such that it overcomes the subregional context involving outer Italian and European stakeholders (see Figure 3c,d).

Figure 3. (a) Cantiere Maggese Urban Center (Taranto-Italy) benches and plant rack made with the population. (b) A moment of participation. (c) Ex-Fadda Urban Center, San Vito dei Normanni (Brindisi, Italy): interiors during the renewal stage. (d) Working with the population and disabled people. [photos@Luigi Oliva].
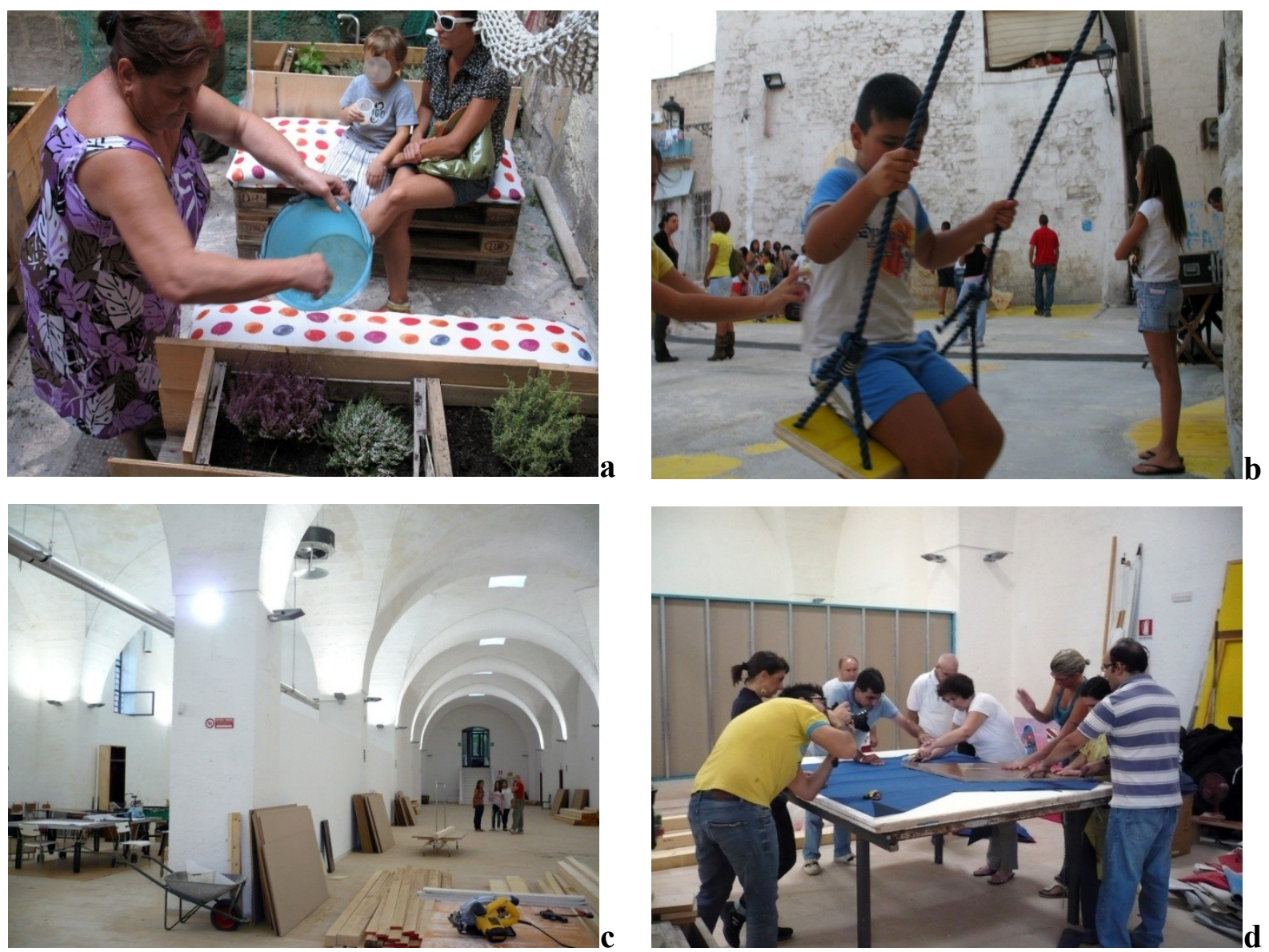

\subsection{The Connotation of User's Sensitiveness towards Building Automation}

The buildings that compose the modern city are places of flows, energy and matter that, using a biological metaphor, can be associated to vital fluids and to their transport of necessary substances to be absorbed or expelled by the organism: a "urban metabolism" [35]. In the classical configuration of urban services, these flows are not associated to a piece of information. For example, their flow is almost unconscious and without meaning to the inhabitants' intelligences. The classical plant design paradigm that divides the connections of the building from the urban plant design in suppliers and waste connections produces a simple binary system: input, which is to consume, and output, which is to throw away. 
Complexity develops at the district level of the plant's grid, where the input and output of the buildings that make up the settlement are collected. Yet, such complexity takes on a meaning only for the plant designer and the network supplier, who are in charge of connecting the boundaries of buildings. The contemporary development of innovative IT systems - their technological application in the energetic field (thermal/electric) and hydraulics - and of a systemic culture able to observe the flows that are located in open places is stimulating a perceptive reaction in the inhabitants of cities. It is therefore possible to interact with these flows through new tools: energy and matter flows are loaded with information and open new connection paths among users.

Connections are not only spatial, but they stimulate time projection. The conception of an energy production plant based on local and private solar photovoltaic panels, is, in this sense, strongly representative of the intensification of space-time connections. Local production, the production of the owner of that plant, is subject to the intermittence typical of solar radiation availability. The user-producer knows that he will use less electricity in the period of maximum plant production; the excess will end up in the network connection, in an opposite way to the supply and different from dumping, namely charging other buildings in a different place. The development of home automated control systems of the so-called domotics and its implications were foretold and explored in the recent past, when the level of development of technological tools could be imagined, but not applied systematically. These were enlightened intellectual visions, but not yet able to determine significant and widespread behavioral variations. However, the "domineering" aspect of these technologies has been often highlighted by underlying the subjection of the inhabitant to the difficulties of the domotic system. Recently, the diffusion of tablets and smartphones that can be easily connected to domotic switchboards is giving a boost to domotics and network connections. Domotic technologies are user-friendly, reassuring and worth-while. The ethics of this diffusion is tenuously ecologist, devoted to save resources and reduce waste through the re-use of dumping flows.

It is a new relationship altogether, between energy flows and mass that pass through buildings, which, as mentioned before, stimulate an "extended sensitivity" in the citizen. Some authors focused their studies on coupling different levels of the city-system. For example, in the Swedish case study of Hammarby Sjöstad in Stockholm [36], the connection among scales clearly stands out, which is fundamental in these projects [37] (see Figure 4).

This vision is not far from the balance of some pre-industrial, agricultural and traditional settlements. The fundamental difference is in the scales of interaction, from a single building to a modern area with an elevated inhabitative density, to a city, village, and more. The rediscovery of a cyclical approach is not only the result of an ecologist ethos, since Hammarby's system was born to be advantageous to its own inhabitants. It is rather, a technological-cultural reconfiguration of the role of IT systems as a way to involve people in managing a plant organization. A system that is articulated on more than one spatial and time-scale requires the availability of mediation resources with an autonomous programmed management of artificial intelligence - to be able to work and adapt to all variations and intermittences linked to users and natural rhythms.

Flows, as it were, take on a meaning linked to opposed needs to the possible reconciliation of the same needs; they organize themselves in a language that is conveyed through the gauges of these flows. Their numeric values stimulate a new control on those technological elements by the inhabitant, which construction industrialization has standardized and pushed away from the buyer during the past century. 
Figure 4. Scale connections in the Hammarby Sjöstad (from Montrucchio, 2012).

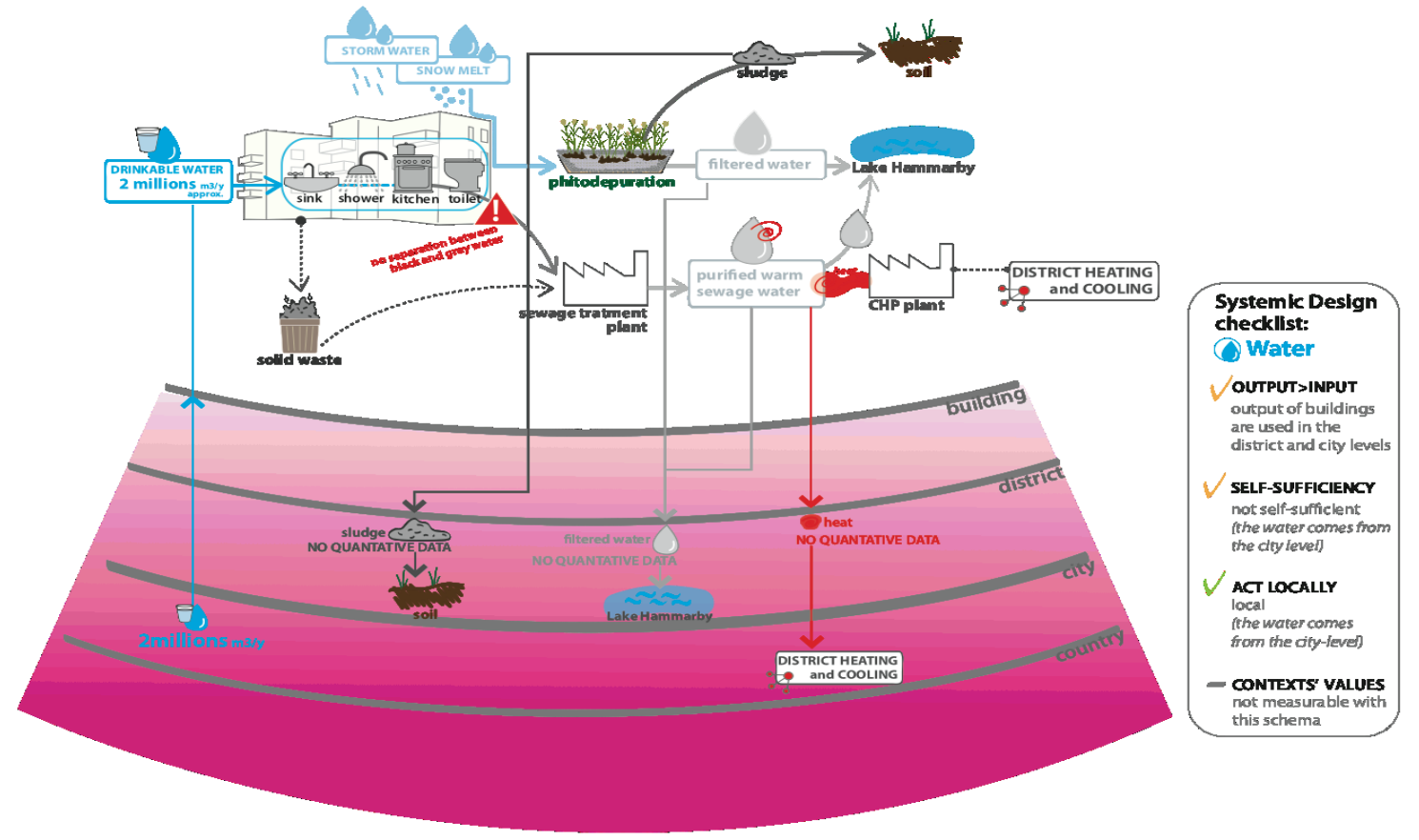

Recently, connections between inhabitants of a building and the rest of the urban territory have been often tested to achieve a new ecological balance. The connotation of user's sensitiveness towards building automation (domotics) is the main cipher of some recent products, based on the use of economic components and on a free programming language. These are non-engineered systems sold as a rigid product, a series of technological components that allow one to build one's own domotics through optimized tools. These open-source electronics prototyping platforms can be connected to every type of sensor and control, useful for managing the functions of a modern building, like central heating, natural and artificial daylight and the popular systems of energy generation. Each appliance can be used for a variety of original applications and self-built ones. The Internet is the natural ground where users' communities of these economic systems are extremely powerful, flexible and proliferate.

\section{Conclusions}

The two-fold objective of this article is, on the one hand, to show how disciplinary crossbreeding can produce scientific supports necessary to promote innovation and improvements in institutional and social practices at a theoretical level; on the other hand, to briefly present some case studies where such innovations have been applied. These case studies also offer a systemic vision of the "participatory and complex management of the design process" issue and of the final object, i.e., the technological systems at the urban scale and the interactive museum at the architectural scale.

The question of democratic discussion on the future of cities and territories boosts the institutional and disciplinary systems that rule over them. Bottom-up actions confirm the primary will of creating sustainable processes in a socio-environmental scope, prior to any technological processes. The historic town and pre-industrial settlements represent an experiential tank, a set of millenary practices that are still able to become a "collective mind" among groups in order to exchange and work-out innovative solutions through sharing and comparative studies. 
From a technological point of view, the role of IT systems determines the chance for people to be involved in managing organizations with a complex network, rather than a top-down controlled solution. This practical possibility, which is more and more developed, stimulates the sensibility of the inhabitants, which can be involved in the management of the system as actors and proponents. The needs promoted by sustainable development impose the adoption of a systemic vision. The future of a sustainable urban environment lies both in the consideration of informal participative processes as a powerful means for improving the connective quality of urban space and in the role of technology in the collective space definition. The extent of their contribution depends on the resolution to overcome the mystification of fictitious openness and social partnerships, which hide a short-term centralistic planning, influenced by economic speculation.

However, a sectorial approach still endures, anchored to a hierarchical and scarcely communicative organizational structure, typical of local authorities. Scientific research can interact on two fronts: by promoting a critical and in-depth approach about the meaning and social implications of "sustainable development". Indeed, if the objects of a sustainable approach are known, the necessary conditions for sustainability are still undetermined, particularly regarding its long-term effects. On the other hand, research must focus on the development of technologies and innovative tools to manage complexity through a systemic approach. Open access platforms, information and communication technology, but also the "systemic modelling" to the urban and architectural scale can all offer an interesting answer. These tools allow different stakeholders to take part in the decision-making process, establishing an organic representation of reality, so that many subjective perceptions of the same object can be fostered.

In light of this, sharing tools currently represent an opportunity to accompany urban and architectural transformations according to perspectives full of potential, without claiming to outline complex scenarios or to replace a more detailed vision.

\section{Conflict of Interest}

The authors declare no conflict of interest.

\section{References and Notes}

1. De Fusco, R. L'idea di architettura: Storia Della Critica da Viollet-le-Duc a Persico (in Italian), 2nd ed.; FrancoAngeli: Milano, Italy, 2003.

2. Schuldenfrei, E., Yiu, M., Eds. Instant Culture: Architecture and Urbanism as a Collective Pro-Cess; MCCM Creations: Hong Kong, China, 2012.

3. Caiulo, C.; Pallara, S. Architettura, il nuovo che non c'è. In "Il del tutto nuovo", Quaderno di Co-Municazione, Rivista di Dialogo tra Culture (in Italian); Meltemi: Roma, Italy, 2007; pp. 91-100.

4. Kelly, K. What Technology Wants; Viking: New York, NY, USA, 2010.

5. Thackara, J. In the Bubble. Designing in a Complex World; Mit Press: Chicago, IL, USA, 2005.

6. Pellegrino, M.; Maahsen-Milan, A.; Magnaghi, A. Innovation in Urban and Architectural Composition Practices: The Re-Qualification/Regeneration Project of Ile de Nantes as an Example of How Uncertainty Can Be Managed in a Positive Way. In Improving the Quality of Suburban Build-ing Stock-COST Action TU0701; Unife Press: Ferrara, Italy, 2012; pp. 467-472. 
7. Folke, C.; Carpenter, S.; Elmqvist, T.; Gunderson, L.; Holling, C.S.; Walker, B. Resilience and Sustainable Development: Building Adaptive Capacity in a World of Transformations; Edita Norstedts Tryckery Ab: Stockholm, Sweden, 2002.

8. Remotti, F. Cultura. Dalla Complessità all'impoverimento (in Italian); Laterza: Roma-Bari, Italy, 2011.

9. Häckel, E. Kunstformen der Natur (in German); Bibliographisches Institut: Berlin-Leipzig, Germany, 1904.

10. Afuhs, A., Strobl, E., Eds. Hermann Obrist. Skulptur, Raum. Abstraktion um 1900 (in German); Scheidegger \& Spiess: Zürich, Swiss, 2009.

11. Blossfeldt, K. Urformen Der Kunst: Photographische Pflanzenbilder (in German); Verlag Ernst Wasmuth A.G.: Berlin, Germany, 1929.

12. Brunetti, G.L. Frederick, K. L'architettura, l'ambiente. Intervista a Maria Bottero. Costruire in Laterizio; n. 74/2000; Tecniche Nuove: Milano, Italy, 2000; pp. 30-35.

13. Kiesler, F.J. Manifeste du Corréalisme (in French); In L'Architecture d'Aujourd'hui; Archipress \& Associés: Paris, France, 1949.

14. In the sixties and seventies Kiesler influenced architects as Hani Rashid e Lise Anne Couture (Asymptote), Peter Cook, Hans Hollein, Greg Lynn, Frank O’Gehry, Cedric Price.

15. Zanni, F., Ed. Urban Hybridization; Maggioli: Milano, Italy, 2012.

16. Maahsen-Milan, A.; Pellegrino, M. Futurama. Il Mito Magmatico Dell'innovazione in Architettura. In "Rete Vitruvio", Procedia, 1st International Congress "Architecturale Design between Teaching and Research"; PolibaPress: Bari, Italy, 2011; Volume 2**, pp. 997-1006.

17. Novak, M. Babele 2000 (in Italian). Available online: http://www.trax.it/marcos_novak.htm (accessed on 1 July 2013).

18. De Kerckove, D. Brainframes: Technology, Mind and Business; Bosch \& Keuning: Baarn, The Netherlands, 1991.

19. De Bono, E. Lateral Thinking: Creativity Step by Step; Harper \& Row: New York, NY, USA, 1970.

20. Among the most interesting crossbreeding networks: ManifeTSo (Trieste) and Spazi Indecisi (Forli).

21. Minucci, F. L'evoluzione del Governo del Territorio e Dell'ambiente. Dalla Logica dei Comandi Alle Logiche Condivise (in Italian); UTET: Torino, Italy, 2005.

22. Sassen, S. A Sociology of Globalization; W.W. Norton: New York, NY, USA, 2007.

23. Bulot, T. Le Français, les Langues et les Villes. In Dynamiques de la Langue Française au 21ième siècle. Une Introduction à la Sociolinguistique (in French); Bulot, T., Blanchet, P., Eds. Available online: http://www.sociolinguistique.fr (accessed on 28 June 2013).

24. Dalisi, R. Architettura D'animazione. Cultura di Proletariato e Lavoro di Quartiere a Napoli (in Italian); B. Carucci: Roma-Assisi, Italy, 1975.

25. Città: Architettura e Società. 10. Mostra Internazionale di Architettura. La Biennale di Venezia (in Italian); Burdett, R., Ed.; Marsilio: Venezia, Italy, 2006.

26. De Rosa, A.S. Turisti di sei nazionalità per la prima volta nella "città eterna": "Place Identity" e Rappresentazioni Sociali di Roma e del suo Centro Storico. In Conoscere e Rappresentare la città. AMBIENTE Urbano tra Architettura e Psicologia (in Italian); Nenci, A.M., Ed.; Cedam: Padova, Italy, 1997; pp. 149-214. 
27. Korac, M. Remaking home. Reconstructing life, place and identity in Rome and Amsterdam; Berghahn Books: New York, NY, USA, 2009.

28. Elkadi, H., Forsyth, K. Piazza Vittorio: La trasformazione urbanistica. Quale identità per i nuovi cittadini? Identity and meaningful place making (in Italian and English); EDUP: Roma, Italy, 2009.

29. Binanti, L. Il Bambino e la città. In L'accoglienza del Bambino Nella Città Globale (in Italian); Limone, P., Ed.; Armando Editore: Roma, Italy, 2007; pp. 51-62.

30. Zerubavel, E. Time Maps: Collective Memory and the Social Shape of the Past; University of Chicago Press: Chicago, IL, USA, 2003.

31. More information on the workshops: "Parkurka", "Terrarret" and "Chi usa la tana del polpo" are available on Labuat's blog. Available online: http://labuat.wordpress.com (in Italian) (accessed on 28 June 2013).

32. Oliva, L.; Forastiere, S. Il Progetto di Architettura nei Centri Storici Degradati: il Caso Studio di Ta-Ranto. In Procedia, 1st International Congress "Architecturale Design between Teaching and Research"; PolibaPress: Bari, Italy, 2011; Volum 3, p. 1037.

33. European Commission, Culture Programme 2007-2013: Directorate-General For Education And Culture, Education. Available online: http://eacea.ec.europa.eu/culture/index_en.php (accessed on 28 June 2013).

34. Exfadda. IDEEXTRALARGE Home Page (in Italian). Available online: http://www.exfadda.it/ (accessed on 28 June 2013).

35. Moaavenzadeh, F.; Hanaki, K.; Baccini, P. Future Cities: Dynamics And Sustainability; Kluwe Academic Publishers: Dordrecht, The Netherlands, 2002.

36. GlashusEtt. Hammarby Sjöstad: A Unique Environmental Project in Stockholm; GlashusEtt: Stockholm, Sweden, 2007.

37. Montrucchio, V.; Simonetti, M. The systemic design approach applied to the analysis of buildings. Int. J. Design Manag. Prof. Pract. 2013, 6, 97-113.

(C) 2013 by the authors; licensee MDPI, Basel, Switzerland. This article is an open access article distributed under the terms and conditions of the Creative Commons Attribution license (http://creativecommons.org/licenses/by/3.0/). 